\title{
PENGARUH EMPLOYEE ENGAGEMENT TERHADAP KEPUASAN KERJA DENGAN WORK LIFE BALANCE SEBAGAI VARIABEL INTERVENING
}

\author{
Noufal Ahmadi Atthohiri \\ Universitas Negeri Surabaya \\ noufal.17080574121@unesa.ac.id \\ Dewie Tri Wijayati \\ Universitas Negeri Surabaya \\ dewiewijayati@unesa.ac.id
}

\begin{abstract}
Land public transportation modes are experiencing a significant increase after constructing the Trans Java toll road. Many bus companies maximize the use of the Trans Java toll road to serve the community, one of these companies is PT. Haryanto Motor Indonesia. This company is engaged in Autobus Transportation. This study aims to determine the effect of employee engagement on job satisfaction with work-life balance as an intervening variable. This type of research is quantitative with 66 employees using purposive sampling technique with criteria is all of the respondents have worked in east java. The statistical analysis technique used is Partial Least Square with the help of SmartPLS 3 software. The results obtained from the study explain that employee engagement has a positive but not significant effect on job satisfaction, employee engagement has a positive and significant effect on work-life balance, work-life balance has a significant positive effect. On job satisfaction and work-life balance can mediate with full mediation category. The implication of this research is in terms of job satisfaction; the company may be able to add labour guarantees to its employees to increase the sense of security and satisfaction of the employees.
\end{abstract}

Keywords: employee engagement; job satisfaction; work-life balance.

\section{PENDAHULUAN}

Perkembangan perusahaan transportasi darat meningkat seiring dibangunnya Tol Trans Jawa karena mobilitas masyarakat yang semakin mudah (Novenanto, 2018). Hal ini mengakibatkan perkembangan moda transportasi bus begitu pesat ditandai dengan munculnya kelas baru, yaitu sleeper class untuk memenuhi kebutuhan konsumen khususnya untuk bus AKAP (Antar Kota, Antar Propinsi) (Hipwee, 2020). Perkembangan transportasi bus mengakibatkan kru bus bekerja lebih dari 8-12 jam (Kompas, 2019).

Penumpang bus memilih perusahaan atau armada favorit dengan memertimbangkan faktor kenyamanan, pelayanan, biaya, dan waktu tempuh (Kwanto \& Arliansyah, 2016). Dari faktor tersebut perusahaan akan semakin memerhatikan kru bis/karyawan mereka yang berhubungan langsung dengan konsumen (Hipwee, 2020). Kunci perusahaan untuk dapat melayani konsumen dengan baik, salah satunya adalah aspek kepuasan kerja para karyawan (Bonn, 2018). (Wijayati et al., 2020) menyatakan bahwa kepuasan kerja ialah wujud dari perasaan karyawan yang muncul akibat faktorfaktor yang berhubungan antara pekerjaan dan kebutuhan materi dan psikologis.

Aspek psikologis yang perlu dibangun adalah employee engagement (Kristanti et al., 2017). Employee engagement merupakan kunci untuk menjaga kualitas pelayanan sebuah usaha di bidang Jasa (Ramadhan \& Sembiring, 2017). Bakker \& Schaufeli (2006) mengatakan bahwa employee engagement dicirikan dengan adanya gairah (vigor), dedikasi dalam bekerja (dedication), dan penghayatan selama bekerja (absorption), ketiga hal tersebut mengakibatkan rasa keterlibatan yang tinggi sehingga membuat karyawan merasa positif dan puas. Dijelaskan oleh Widjaja et al. (2017) bahwa employee engagement berpengaruh positif signifikan terhadap kepuasan kerja.

Aspek selain employee engagement dapat memengaruhi tingkat kepuasan kerja salah satunya adalah work life balance, semakin seimbang hubungan antara pekerjaan dan kehidupan non kerja akan 
memengaruhi tingkat kepuasan kerja (Ganapathi, 2016). Armstrong et al. (2015) mengatakan semakin tinggi tingkat kepuasan kerja menandakan semakin rendahnya tingkat konflik di dalam keluarga atau bisa diartikan tingkat work life balance tinggi. Rasa kepuasan dan kebahagiaan selama bekerja dan kehidupan rumah tanpa adanya konflik diantara kedua hal tersebut bisa diartikan sebagai work life balance (Ariawaty, 2019). Mas-Machuca et al. (2016) menjelaskan hubungan work life balance terhadap kepuasan kerja merupakan hubungan yang positif signifikan.

Sirgy \& Lee (2018) menjelaskan bahwasanya work life balance merupakan bentuk engagement yang tinggi dalam kehidupan kerja serta kehidupan non-kerja dengan terciptanya konflik yang sedikit antara peran sosial dalam pekerjaan dan kehidupan non-kerja. Penelitian Wood et al. (2020) menghasilkan hubungan signifikan negatif antara employee engagement dengan work life balance, di mana semakin tinggi employee engagement maka semakin tidak seimbang kehidupan di luar pekerjaannya. Iqbal et al. (2017) menjelaskan hasil yang berbeda, yaitu hubungan antara employee engagement dengan work life balance adalah positif signifikan.

Berdasarkan hasil wawancara, para kru bus PT. Haryanto Motor Indonesia merasa kebanyakan bekerja lebih dari 12 jam, namun hampir semuanya merasa mampu menyeimbangkan hubungan antara pekerjaan dan rumah dan mereka merasa puas dalam bekerja. Atas dasar hal tersebut, tujuan penelitian ini adalah untuk menganalisis pengaruh employee engagement terhadap kepuasan kerja dengan melalui work life balance. Penelitian ini diharapkan akan memerjelas gap research yang terjadi antara employee engagement dengan work life balance dan memerjelas peranan work life

\section{KAJIAN PUSTAKA DAN PENGEMBANGAN HIPOTESIS}

\section{Employee Engagement}

Perasaan engaged merupakan suatu keterhubungan, keterlibatan, komitmen, kesetiaan, rasa memiliki terhadap perusahaan, keinginan berkontribusi terhadap perusahaan, dan rasa bangga terhadap pekerjaan dan juga perusahaannya (Macey \& Schneider, 2008). Sedangkan Bakker \& Schaufeli, (2006) mengatakan employee engagement mengatakan bahwa employee engagement dicirikan dengan adanya gairah (vigor), dedikasi dalam bekerja (dedication), dan penghayatan selama bekerja (absorption), ketiga hal tersebut dianggap sebagai pandangan hidup yang positif dan pemikiran tentang kesatuan hubungan kerja akibatnya karyawan dengan keterlibatan yang tinggi akan merasa positif dan puas. Employee engagement merupakan bentuk kontribusi langsung karyawan terhadap pekerjaannya yang dapat dilihat melalui semangat, dedikasi, dan penghayatannya (Nimon et al., 2015). Ketika karyawan engaged, mereka akan memiliki suatu kesadaran perannya sehingga dapat memberikan seluruh kemampuan terbaiknya (Rachman \& Dewanto, 2016). Menurut Rachman \& Dewanto, (2016) pembahasan employee engagement pada bidang sumber daya manusia di Indonesia masih terbilang sedikit, ini dapat dilihat dari sedikitnya penelitian yang menyinggung perihal employee engagement. Sejatinya employee engagement dapat digunakan sebagai refleksi atas perilaku karyawan dan kinerja perusahaan (Ariawaty, 2019).

\section{Work Life Balance}

Work life balance umumnya dikaitkan oleh berbagai aspek kehidupan seseorang (Maslichah \& Hidayat, 2017). Work life balance dapat diartikan sebagai bukti tidak adanya konflik diantara kehidupan kerja maupun kehidupan rumah sehingga akan tercipta keseimbangan kepuasan dan kebahagiaan (Ariawaty, 2019). Sirgy \& Lee (2018) menjelaskan hal yang sama bahwa work life balance merupakan bentuk engaged yang tinggi dari seseorang pada kehidupan kerja dan non-kerja, dengan dibuktikan sedikitnya permasalahan yang terkait antara kehidupan kerja dan non kerja. Raja \& Ganesan Kanagaraj, (2020) mendukung hal tersebut, bahwa work life balance adalah terciptanya keseimbangan dan keterlibatan karyawan terkait waktu, dan peran antara kehidupan kerja dan nonkerja. Iswardhani et al. (2019) mengatakan bahwa apabila karyawan memiliki keseimbangan kerja dan non-kerja yang tinggi yang dapat membuat mereka puas, hal tersebut akan memicu munculnya etos kerja yang tinggi, dan memberikan kontribusi yang positif, karena apabila pekerjaan yang menyita waktu lebih banyak dibanding keluarga nantinya akan memunculkan work family conflict (Wijayati et al., 2020). 


\section{Kepuasan Kerja}

Kepuasan kerja merupakan kondisi di mana para karyawan merasa puas atas apa yang mereka dapat selama bekerja (Bowling, 2017). Wijayati et al. (2020) menjelaskan kepuasan kerja pada dasarnya merupakan urusan dari masing-masing individu yang memiliki tingkat kepuasan berbeda-beda berdasarkan dengan nilai yang berlaku pada setiap individu tersebut. Hal ini menandakan bahwa kepuasan kerja diperoleh ketika karyawan puas dengan gaji, lingkungan kerja, dan pekerjaan itu sendiri (Wibawa, 2016). Tingkat kepuasan kerja juga ditandai dengan tidak adanya konflik pekerjaan dengan keluarga keluarga (Armstrong et al., 2015).

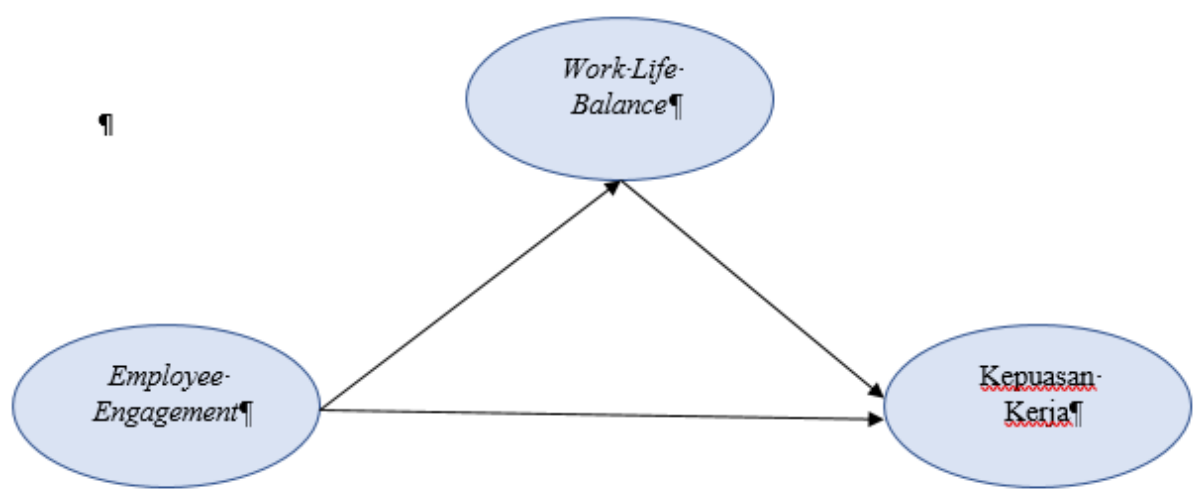

\section{Gambar 1. KERANGKA KONSEPTUAL}

\section{Hubungan antar Variabel}

Widjaja et al. (2017) menjelaskan hubungan yang terjadi bahwa employee engagement bisa memiliki pengaruh positif signifikan terhadap kepuasan kerja. Hasil penelitian tersebut mendukung penelitian Haryanto et al. (2018), Al-dalahmeh et al. (2018) dan Saptono \& Supriyadi (2020). Tetapi Fauziridwan, (2019) menjelaskan hasil yang berbeda bahwa employee engagement berhubungan positif namun tidak ada pengaruh yang signifikan.

H1: Employee engagement memengaruhi kepuasan kerja secara positif dan signifikan.

Wood et al., (2020) melalui metode literature review menunjukkan ada dua hasil yang terjadi, yaitu employee engagement berpengaruh positif, dan dapat berpengaruh negatif kepada work life balance. Namun Reio \& Ghosh (2009) memeroleh hasil penelitian yang berbeda, yaitu employee engagement memberikan pengaruh negatif kepada work life balance. Sedangkan penelitian Iqbal et al. (2017) employee engagement memengaruhi work life balance secara positif dan signifikan.

$\mathrm{H} 2$ : Employee engagement memengaruhi work life balance secara positif dan signifikan.

Rachman \& Dewanto, (2016) menjelaskan adanya hubungan yang positif tetapi tidak signifikan di antara employee engagement dengan work life balance. Aliya \& Saragih, (2020), Rene \& Wahyuni, (2018), Ganapathi (2016) menjelaskan hasil yang berbeda, apabila terjadi peningkatan work life balance akan memberikan pengaruh positif signifikan terhadap kepuasan kerja, yang nantinya akan mendorong juga meningkatnya kepuasan kerja para karyawan, hal ini bisa dikatakan bahwa hubungan antara work life balance dengan kepuasan kerja.

H3: Employee engagement memberikan pengaruh positif signifikan terhadap work life balance.

Wood et al. (2020) membahas tentang posisi work life balance sebagai mediasi dan mediator. Penelitian tentang pengaruh hubungan employee engagement terhadap kepuasan kerja dengan melalui work life balance, belum ditemukan bentuk variabel atau kerangka konseptual yang sama di Indonesia. 
Noufal Ahmadi Atthohiri \& Dewie Tri Wijayati. Pengaruh Employee Engagement terhadap Kepuasan Kerja dengan Work Life Balance sebagai Variabel Intervening

H4 : Ada pengaruh hubungan positif signifikan yang terjadi di antara employee engagement dengan kepuasan kerja bila melalui work life balance.

\section{METODE PENELITIAN}

Metode penelitian yang digunakan adalah kuantitatif. Sumber data berasal dari data kuisioner yang dibagikan kepada calon responden dan juga didukung dengan wawancara tidak sistematis. Kuisioner menggunakan skala likert dengan skala nilai 1 yang berarti sangat tidak setuju sampai skala 5 yang berarti sangat setuju. Populasi merupakan seluruh kru bus PT. Haryanto Motor Indonesia. Sampel yang dipilih adalah 66 orang kru bus, semuanya dipilih menggunakan non probability sampling yaitu purposive sampling, dengan kriteria yang ditetapkan adalah seluruh responden merupakan kru bus yang bekerja untuk trayek Jawa Timur sampai Jakarta. Data yang diperoleh dianalisis dengan Structural Equation Modeling (SEM) menggunakan metode alternatif yaitu Partial Least Square (PLS) dengan software SmartPLS 3.

\section{HASIL DAN PEMBAHASAN}

\section{Uji Validitas}

Indikator dikatakan valid apabila memiliki nilai outer loading $\geq 0,70$ dan memiliki nilai Average Variance Extracted (AVE) $\geq 0,5$ (Ghozali, 2015).

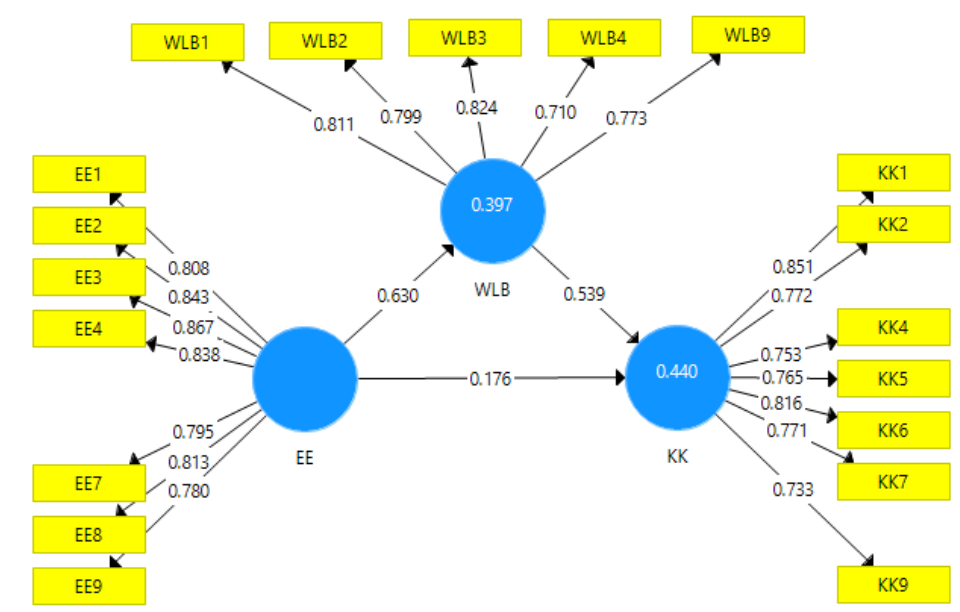

Sumber : Hasil SmartPLS 3, 2021

Gambar 2. MEASUREMENT MODEL

Gambar 2. nilai outer loading setiap indikator berada di atas 0,70. Namun pada indikator EE5 dan EE6 variabel employee engagement nilai outer loading di bawah 0,70. Indikator WLB5, WLB6, WLB7, WLB8 nilai outer loading indikator work life balance di bawah 0,70 dan indikator KK3, KK8 sebagai indikator kepuasan kerja yang memiliki outer loading di bawah 0,70. Semua indikator dengan outer loading berada di bawah 0.70 harus dihapus, dan di running kembali. Hasilnya dapat membuktikan bahwa tidak ada indikator yang berada di bawah kriteria.

Tabel 1.

AVERAGE VARIANCE EXTRACTED

\begin{tabular}{ccc}
\hline Variabel & Nilai AVE & Keterangan \\
\hline Employee engagement $(\mathrm{X})$ & 0,674 & Valid \\
Work life balance $(\mathrm{Z})$ & 0,610 & Valid \\
Kepuasan kerja $(\mathrm{Y})$ & 0,615 & Valid \\
\hline
\end{tabular}

Sumber : Hasil SmartPLS 3 
Tabel 1. nilai AVE membuktikan seluruh indikator pada setiap variabel semuanya valid dikarenakan nilai AVE berada di atas 0,5 .

\section{Uji Reliabilitas}

Uji Reliabilitias pada penelitian ini digunakan dua cara, yang pertama ialah melihat nilai cronbach's alpha, kemudian yang kedua dengan menggunakan composite reliability.

Tabel 2.

\section{CRONBACH'S APLHA DAN COMPOSITE RELIABILITY}

\begin{tabular}{lccc}
\hline \multicolumn{1}{c}{ Variabel } & Cronbach's Aplha & Composite Reliability & Keterangan \\
\hline Employee engagement $(\mathrm{X})$ & 0,919 & 0,935 & Reliabel \\
Work life balance $(\mathrm{Z})$ & 0,894 & 0,916 & Reliabel \\
Kepuasan kerja (Y) & 0,845 & 0,888 & Reliabel \\
\hline
\end{tabular}

Sumber: Hasil SmartPLS 3 (2021).

Tabel 2. nilai cronbach's alpha maupun nilai composite reliability semua variabel berada di atas 0,70 , artinya semua variabel sudah melebihi kriteria minimum sehingga ketiga variabel tersebut memiliki reliabilitas yang kuat.

\section{Analisis R-Square}

Hasil analisis $R$-Square, employee engagement memengaruhi kepuasan kerja dengan nilai 0,440, artinya kepuasan kerja dipengaruhi oleh employee engagement sebesar 44\%, sisanya dipengaruhi oleh variabel yang lain. Work life balance dengan nilai $R$-Square sebesar 0,397, artinya employee engagement hanya memengaruhi variabel work life balance sebesar $39,7 \%$.

\section{Uji Kausalitas}

Berdasarkan tabel 3. pengaruh variabel employee engagement terhadap kepuasan kerja memiliki hubungan positif. Kepuasan kerja berhubungan positif ke work life balance. Variabel work life balance berhubungan positif terhadap kepuasan kerja. Hubungan tidak langsung yang terjadi antara ketiga variabel pun bersifat positif.

Variabel employee engagement terhadap kepuasan kerja memiliki hubungan langsung dengan p-value 0.302 dan nilai t-statistik 1,034 yang berarti kedua nilai tersebut tidak memenuhi kriteria, sehingga hipotesis ditolak dan membuktikan bahwa employee engagement tidak memengaruhi kepuasan kerja dengan signifikan. Pengaruh variabel employee engagement terhadap work life balance ditandai dengan nilai p-value 0.000 dan nilai t-statistik 8,412 yang nilai tersebut telah memenuhi kriteria yang dipersyaratkan, sehingga hipotesis dapat diterima dan terbukti employee engagement dapat memengaruhi work life balance dengan signifikan. Pengaruh diantara variabel work life balance dengan kepuasan kerja memiliki p-value 0.000 dan nilai t-statistik 3,997 yang berarti telah memenuhi kriteria akibatnya hipotesis dapat diterima dan work life balance memengaruhi kepuasan kerja secara signifikan.

Tabel 3.

HASIL PATH COEFFICIENT

\begin{tabular}{lccc}
\hline \multicolumn{1}{c}{ Hubungan antar Variabel } & T-Statistik & P-Value & Keterangan \\
\hline Hubungan Langsung & & & \\
$\quad$ Employee engagement $\rightarrow$ Kepuasan Kerja & 1,034 & 0,302 & Hipotesis Ditolak \\
$\quad \begin{array}{l}\text { Employee engagement } \rightarrow \text { Work life balance } \\
\quad \text { Work life balance } \rightarrow \text { Kepuasan kerja }\end{array}$ & 8,412 & 0,000 & Hipotesis Diterima \\
$\quad \begin{array}{l}\text { Hubungan Tidak Langsung } \\
\quad \text { Employee engagement } \rightarrow \text { Work life balance } \rightarrow\end{array}$ & 3,997 & 0,000 & Hipotesis Diterima \\
$\quad$ Kepuasan kerja & 3,237 & 0,001 & Hipotesis Diterima \\
\hline
\end{tabular}

Sumber: Hasil SmartPLS 3 (2021) 
Noufal Ahmadi Atthohiri \& Dewie Tri Wijayati. Pengaruh Employee Engagement terhadap Kepuasan Kerja dengan Work Life Balance sebagai Variabel Intervening

Tabel 3. besarnya koefisien hubungan tidak langsung antara employee engagement dengan kepuasan kerja melalui work life balance memiliki nilai t-statistik 3,237 dan p-value 0.000. Artinya variabel work life balance berpengaruh signifikan.

\section{Pengaruh Employee Engagement terhadap Kepuasan Kerja}

Hasil pengujian menunjukkan tidak ada pengaruh yang signifikan antara employee engagement terhadap kepuasan kerja pada kru bus PT. Haryanto Motor Indonesia. Hasil dari penelitian ini mendukung (Fauziridwan, 2019) bahwa variabel employee engagement memengaruhi kepuasan kerja dengan positif tetapi tidak signifikan. Namun berbeda dengan Setiawan et al. (2019), Ravelby et al. (2020), dan (Kristanti et al., 2017) bahwa variabel employee engagement memengaruhi kepuasan kerja secara positif dan signifikan. Hasil penelitian menjelaskan keterlibatan kru bus yang tinggi tidak menjadi faktor yang memengaruhi tingkat kepuasan kerja para kru bus PT. Haryanto Motor Indonesia.

Hasil wawancara tidak terstruktur juga memeroleh informasi terkait hal tersebut. Menurut responden keterlibatan mereka selama ini belum sampai pada titik yang dapat memengaruhi terhadap tingkat kepuasan terhadap pekerjaan, hanya sebatas kesadaran bahwa mereka harus memberikan yang terbaik kepada para konsumen.

\section{Pengaruh Employee Engagement terhadap Work Life Balance}

Employee engagement berpengaruh terhadap work life balance. Hasil tersebut mendukung penelitian Ariawaty et al. (2019) dan Iqbal et al. (2017), yang membuktikan ada hubungan positif signifikan diantara kedua variabel. Hasil tersebut memberikan makna bahwa semakin tinggi keterlibatan karyawan semakin tinggi pula tingkat work life balance. Dengan kata lain, kru bus merasa dengan keterlibatan yang tinggi tidak akan mengurangi tingkat keseimbangan kehidupan kru bus PT. Haryanto Motor Indonesia. Jaharuddin \& Zainol, (2019) menjelaskan hal yang berbeda, dimana employee engagement berpengaruh negatif signifikan terhadap work life balance.

Hasil wawancara tidak terstruktur yang dilakukan terhadap kru bus mampu menjelaskan hasil tersebut, yang mana keterlibatan kru bus di pekerjaan yang tinggi dapat mengakibatkan peningkatan terhadap work life balance para karyawan dikarenakan kesadaran yang timbul atas pekerjaan yang dijalani.

\section{Pengaruh Work Life Balance terhadap Kepuasan Kerja}

Setelah dilakukan pengujian hasilnya adalah work life balance berpengaruh positif signifikan terhadap kepuasan kerja. Hasil tersebut mendukung penelitian Ganapathi (2016), Maslichah \& Hidayat (2017), Rene \& Wahyuni (2018), Aliya \& Saragih (2020), dan Saptono \& Supriyadi (2020), bahwa work life balance memengaruhi kepuasan kerja secara positif dan signifikan. Rachman \& Dewanto, (2016) menjelaskan bahwa work life balance hanya sebatas berhubungan positif namun tidak berpengaruh signifikan

Hasil dari wawancara tidak terstruktur diperoleh informasi bahwa kru bus PT. Haryanto Motor Indonesia merasa cukup mampu menyeimbangkan kehidupan pekerjaan dengan keluarga. Wawancara dengan salah satu manager dibagian personalia menjelaskan, penyebab dari hal ini bisa terjadi dikarenakan adanya rekrutmen kru yang mengutamakan domisili mereka sesuai dengan trayek bus tersebut.

\section{Pengaruh Employee Engagement terhadap Kepuasan Kerja dengan dimediasi oleh Work Life Balance}

Hasil penelitian hubungan employee engagement terhadap kepuasan kerja ketika dimediasi oleh work life balance dapat dilihat dengan membandingkan berdasarkan dua penelitian. Pertama, hubungan employee engagement terhadap kepuasan kerja yang tidak berpengaruh signifikan, yang kedua hasil penelitian hubungan tidak langsung employee engagement terhadap kepuasan kerja ketika dilakukan mediasi oleh work life balance mampu memberikan pengaruh yang signifikan. Dari hasil path coefficient tersebut work life balance mampu menjadi variabel mediasi yang bersifat full mediation. 
Hasil itu mendukung hasil penelitian Wood et al. (2020) bahwa work life balance dapat menjadi variabel yang bersifat full mediation.

\section{KESIMPULAN}

Berdasarkan hasil penelitian, pengaruh employee engagement terhadap kepuasan kerja dengan work life balance sebagai variabel intervening yang dilakukan kepada kru bus PT. Haryanto Motor Indonesia dapat disimpulkan: (1) pengaruh antara employee engagement terhadap kepuasan kerja adalah tidak berpengaruh signifikan; (2) pengaruh antara employee engagement terhadap work life balance adalah berpengaruh signifikan positif; (3) work life balance memengaruhi kepuasan kerja secara positif dan signifikan; (4) pengaruh employee engagement terhadap kepuasan kerja apabila dimediasi work life balance membuktikan bahwa work life balance mampu menjadi variabel intervening dengan sifat full mediation.

Setelah dilakukan wawancara dan penelitian, secara umum nilai dari variabel kepuasan kerja sudah sangat tinggi terbukti dengan hasil kuisioner, namun pada item pernyataan jaminan perlindungan karyawan perlu ditingkatkan karena menjadi nilai paling rendah, caranya dengan mendaftarkan para kru bus ke BPJS Tenaga Kerja. Bagi penelitian selanjutnya untuk indikator variabel employee engagement bisa menggunakan indikator yang lain untuk menguji lebih lanjut hasil dari penelitian ini atau bisa menambah variabel yang lain agar lebih kompleks lagi terutama di dunia transportasi, khususnya dunia transportasi darat.

\section{DAFTAR PUSTAKA}

Al-dalahmeh, M., Masa'deh, R., Abu Khalaf, R. K., \& Obeidat, B. Y. (2018). The Effect of Employee Engagement on Organizational Performance Via the Mediating Role of Job Satisfaction: The Case of IT Employees in Jordanian Banking Sector. Modern Applied Science, 12(6), 17. https://doi.org/10.5539/mas.v12n6p17

Aliya, G. R., \& Saragih, R. (2020). Pengaruh Work-Life Balance dan Lingkungan Kerja terhadap Kepuasan Kerja Karyawan di PT Telkom Divisi Telkom Regional III Jawa Barat. Jurnal Ilmiah MEA (Manajemen, Ekonomi, Dan Akuntansi), 4(3), 84-95. https://journal.stiemb.ac.id/index.php/mea/article/download/291/207

Ariawaty, R. R. N. (2019). Pengaruh Employee Engagement terhadap Work-Life Balance Karyawan. Bisma, 13(2), 97. https://doi.org/10.19184/bisma.v13i2.9864

Ariawaty, R. R. N., \& Cahyani, M. D. (2019). Pengaruh Employee Engagement terhadap Work Life Balance Karyawan. Bisma, 13(2), 97-104.

Armstrong, G. S., Atkin-Plunk, C. A., \& Wells, J. (2015). The Relationship Between Work-Family Conflict, Correctional Officer Job Stress, and Job Satisfaction. Criminal Justice and Behavior, 42(10), 1066-1082. https://doi.org/10.1177/0093854815582221

Bakker, A. B., \& Schaufeli, W. B. (2006). The Measurement of Short Questionnaire A Cross-National Study. SAGE Publication, 66, 701-716.

Bonn, H. K. M. A. (2018). 기사 (Article) 와 안내문 (Information) [. The Eletronic Library, 34(1), 15.

Bowling, N. A. (2017). The Facet Satisfaction Scale: an Effective Affective Measure of Job Satisfaction Facets. Journal of Business and Psychology. https://doi.org/10.1007/s10869-0179499-4 
Noufal Ahmadi Atthohiri \& Dewie Tri Wijayati. Pengaruh Employee Engagement terhadap Kepuasan Kerja dengan Work Life Balance sebagai Variabel Intervening

Fauziridwan, M. (2019). Pengaruh Employee Engagement dan Kepuasan Kerja terhadap Organizational Citizenship Behavior serta Dampaknya terhadap Turnover Intention. Journal of Advanced Research in Dynamical and Control Systems, 11 (9 Special Issue), 1100-1104. https://doi.org/10.5373/JARDCS/V11/20192677

Ganapathi, I. M. D. (2016). Pengaruh Work Life Balance terhadap Kepuasan Kerja Karyawan (Studi pada PT. Bio Farma Persero). Ecodemica, IV(1), 125-135. http://www.researchgate.net/publication

Ghozali, I. (2015). Konsep, Teknik dan Aplikasi Menggunakan Program SmartPls 3.0. Semarang, Badan Penerbit UNDIP.

Haryanto, R., Fathoni, A., \& Minarsih, M. M. (2018). Pengaruh Karakteristik Pekerjaan, Employee Engagement Dan Motivasi Terhadap Komitmen Organisasi Dengan Kepuasan Kerja Sebagai Intervening Pada PT Eka Farma Di Semarang. Jurnal Manajemen, 2-18.

Hipwee. (2020). 5 Sleeper Bus Mewah yang Bisa Kamu Nikmati di Indonesia. Nggak Kalah Sama Bus di Luar Negeri! https://www.hipwee.com/travel/sleeper-bus-di-indonesia/ diakses 2 Juni 2021

Iqbal, I., Zia-ud-Din, M., Arif, A., Raza, M., \& Ishtiaq, Z. (2017). Impact of Employee Engagement on Work Life Balance with the Moderating Role of Employee Cynicism. International Journal of Academic Research in Business and Social Sciences, 7(6), 1088-1101. https://doi.org/10.6007/ijarbss/v7-i6/3068

Iswardhani, I., Brasit, N., \& Mardiana, R. (2019). The Effect of Work-Life Balance and Burnout on Employee Job Satisfaction. Hasanuddin Journal of Business Strategy, 1(2), 1-13. https://doi.org/10.26487/hjbs.v1i2.212

Jaharuddin, N. S., \& Zainol, L. N. (2019). The Impact of Work-Life Balance on Job Engagement and Turnover Intention. The South East Asian Journal of Management, 13(1). https://doi.org/10.21002/seam.v13i1.10912

Kompas. (2019). Tol Trans Jawa bisa Ubah tatanan bus AKAP. https://otomotif.kompas.com/read/2019/01/07/123804615/tol-trans-jawa-bisa-ubah-tatananbus-akap diakses 2 Juni 2021

Kristanti, S. E., Purnamasari, M., \& Widjaja, D. C. (2017). Pengaruh Employee Engagement terhadap Kepuasan Kerja dan Turn Over Intention di Swiss-Belinn Surabaya. Jurnal Hospitality Dan Manajemen Jasa, 2017, 141-152.

Kwanto, R., \& Arliansyah, J. (2016). Analisis Pemilihan Moda Transportasi Umum antara Transportasi Umum Konvensional dan Transportasi Umum Online di Kota Palembang. Cantilever, 5(2). https://doi.org/10.35139/cantilever.v5i2.41

Macey, W. H., \& Schneider, B. (2008). The Meaning of Employee Engagement.p. Industrial and Organizational Psychology, 1, 3-30.

Mas-Machuca, M., Berbegal-Mirabent, J., \& Alegre, I. (2016). Work-Life Balance and Its Relationship with Organizational Pride and Job Satisfaction. Journal of Managerial Psychology, 31(2), 586-602. https://doi.org/10.1108/JMP-09-2014-0272

Maslichah, N., \& Hidayat, K. (2017). Pengaruh Work-Life Balance dan Lingkungan Kerja terhadap Kepuasan Kerja Karyawan (Studi pada Perawat RS Lavalette Malang Tahun 2016). Jurnal Administrasi Bisnis S1 Universitas Brawijaya, 49(1), 136362. 
Nimon, K., Shuck, B., \& Zigarmi, D. (2015). and Job Satisfaction: A Function of Semantic. Journal of Happiness Studies. https://doi.org/10.1007/s10902-015-9636-6

Novenanto, A. (2018). Transjawa, Pertumbuhan Ekonomi, dan Urbanisasi. Bhumi Jurnal Agraria Dan Pertanahan, 4(2), 123-139.

Rachman, L., \& Dewanto, A. (2016). Pengaruh Employee Engagement terhadap Kepuasan Kerja dan Turnover Intention Perawat (Studi pada Rumah Sakit Wava Husada Kepanjen Malang). Jurnal Aplikasi Manajemen, 14(2). https://doi.org/10.18202/jam23026332.14.2.14

Raja, S., \& Ganesan Kanagaraj, M. (2020). A Conceptual Study of Work Life Balance and Stress Management among Women Employees of It Companies in Chennai. International Journal of Management, 11(2), 23-26. https://doi.org/10.34218/IJM.11.2.2020.003

Ramadhan, N., \& Sembiring, J. (2017). Pengaruh Employee Engagement terhadap Kinerja Karyawan di Human Capital Center PT. Telekomunikasi Indonesia, Tbk. Jurnal Manajemen Indonesia, 14(1), 47. https://doi.org/10.25124/jmi.v14i1.351

Ravelby, T. A., Linda, M. R., \& Nurofik, A. (2020). Pengaruh Self-Efficacy dan Employee Engagement terhadap Kepuasan Kerja Karyawan Perbankan di Padang. Journal MEDIA BINA ILMIAH, 15(4), 4239-4248.

Reio, T., \& Ghosh, R. (2009). Antecedents and Outcomes of Workplace Incivility. Computational Complexity, 2(1), 1-9. https://doi.org/10.1002/hrdq

Rene, R., \& Wahyuni, S. (2018). Pengaruh Work-Life Balance terhadap Komitmen Organisasi, Kepuasan Kerja, dan Motivasi Kerja terhadap Kinerja Individu pada Karyawan Perusahaan Asuransi di Jakarta. Jurnal Manajemen Dan Bisnis Sriwijaya, 16(1), 53-63. https://doi.org/10.29259/jmbs.v16i1.6247

Saptono, N. K., \& Supriyadi, E. (2020). Pengaruh Work Life Balance dan Lingkungan Kerja terhadap Kepuasan Kerja melalui Employee Engagement dengan Kesehatan Mental sebagai Variabel Moderator pada Karyawan Generasi Milenial ( studi kasus : direktorat keuangan PT.Angkasa Pura I ( Persero ). JURNAL EKOBISMAN, 5(2), 88-108.

Setiawan, O. D., \& Widjaja, D. C. (2019). Analisa Pengaruh Employee Engagement Terhadap Kinerja Karyawan dengan Kepuasan Kerja Sebagai Variabel Intervening di Shangri-La Hotel Surabaya. Jurnal Hospitality Dan Manajemen Jasa, 120-134.

Sirgy, M. J., \& Lee, D. J. (2018). Work-Life Balance: an Integrative Review. Applied Research in Quality of Life, 13(1), 229-254. https://doi.org/10.1007/s11482-017-9509-8

Wibawa, N. H. (2016). Pengaruh Employee Engagement terhadap Kepuasan Kerja dan Turnover Intention pada PT. Finnet Indonesia. E-Proceeding of Management, 3(2), 1484-1491.

Wijayati, D. T., Kautsar, A., \& Karwanto, K. (2020). Emotional Intelligence, Work Family Conflict, and Job Satisfaction on Junior High School Teacher's Performance. International Journal of Higher Education, 9(1), 179-188. https://doi.org/10.5430/ijhe.v9n1p179

Wood, J., Oh, J., Park, J., \& Kim, W. (2020). The Relationship Between Work Engagement and Work-Life Balance in Organizations: A Review of the Empirical Research. Human Resource Development Review, 19(3), 240-262. https://doi.org/10.1177/1534484320917560 